\title{
Levels and Predictors of Anxiety, Depression, and Burnout Syndrome in Physicians During the COVID-19 Pandemic
}

\author{
Tibel Tuna ${ }^{1}$ (D) - Selçuk Özdin ${ }^{2}$
}

Accepted: 18 February 2021/ Published online: 14 April 2021

(C) The Author(s), under exclusive licence to Springer Science+Business Media, LLC, part of Springer Nature 2021

\begin{abstract}
This study intended to observe mental symptoms among physicians in Turkey during the COVID-19 pandemic and to investigate the factors leading to such symptoms. The study participants were contacted via their smartphones between April 23 and 27, 2020, and invited to fill out an online questionnaire which included questions from the Hospital Anxiety and Depression Scale (HADS) and the Maslach Burnout Inventory (MBI). The mean age of the 406 physicians who participated in the study was $42.9 \pm 10.1$ years, and $53.4 \%$ were men $(n$ : 217). During the pandemic, $66.7 \%$ had decreased working hours. Lack of COVID-related training, difficulty obtaining personal protective equipment (PPE), working in a COVID unit, and current psychiatric disease were found to be among the predictors of emotional burnout. Female gender, lack of COVID training, difficulty obtaining PPE, working in a COVID unit, and current psychiatric disease predicted desensitization. Facilitating continuous and comprehensive support mechanisms aimed at protecting physicians' mental health is of great importance during epidemics.
\end{abstract}

Keywords Mental health $\cdot$ Depression $\cdot$ Physicians $\cdot$ Risk factors $\cdot$ Burnout

\section{Background}

COVID-19, which was first detected in Wuhan, China at the end of 2019, and which spread rapidly resulting in a pandemic, has become the most important and urgent public health crisis.

Tibel Tuna

tibeltuna@hotmail.com

Selçuk Özdin

selcuk.ozdin@omu.edu.tr

1 Faculty of Medicine, Department of Pulmonary Medicine, Ondokuz Mayıs University, 55132 Atakum, Samsun, Turkey

2 Faculty of Medicine, Psychiatry Clinic, Ondokuz Mayıs University, 55132 Atakum, Samsun, Turkey 
While the entire world is exposed to this critical entity, all healthcare professionals, especially those involved in the diagnosis, treatment, and care of COVID-19 patients, are at high risk of contracting the disease. As of August 8, 2020, the number of cases in Turkey was 232,856, with 5728 deaths. According to the latest information, the reported number of infected health workers was representing approximately $6.5 \%$ of all cases ("İstanbul Medical Association,", 2020). In addition to the current risks posed by the disease, many healthcare professionals may exhibit symptoms of psychological distress and mental illness, even if they are not infected (Jianbo Lai et al., 2020). Studies conducted during the SARS epidemic in 2003 reported that healthcare professionals exhibited various psychiatric symptoms (Lung et al., 2009). Research indicated that healthcare professionals feared infecting their colleagues and families with the disease, experienced feelings of uncertainty and stigmatization and that most were reluctant to work and had high levels of symptoms of anxiety and depression (Bai et al., 2004). In addition, since the COVID-19 pandemic which began in China in December 2019 reached Turkey on March 16, 2020, news reports of the rapid spread of the disease and large numbers of deaths on television and social media further escalated the level of stress associated with the impending threat during that period. Furthermore, mental health deterioration affects the physical health of physicians, also impacting the quality and reliability of care provided to patients (“HASUDER,", 2020).

Unsurprisingly, the healthcare workers who work under intense and risky conditions during a pandemic are affected psychologically. In a meta-analysis conducted during the COVID pandemic, it was stated that symptoms of depression, anxiety, and insomnia were frequently observed in healthcare workers (da Silva and Neto, 2021). In addition, psychiatric traumatization can occur due to various reasons during the pandemic (Brahmi et al., 2020). Various factors may adversely affect the mental health of healthcare professionals during the course of the pandemic, the foremost being occupational risks. These include delayed diagnosis, working in higher risk units, inadequate training, inadequate compliance with safety precautions such as hand hygiene, inadequate or improper use of personal protective equipment (PPE), and prolonged exposure to COVID-19 patients. Irregular working hours, increased workload, and separation from families also result in adverse mental effects ("HASUDER,", 2020). Additional factors that have been found to affect the healthcare workers include having children for prolonged durations at home (Șahin et al., 2020), changes in daily priorities, and housework (Morgantini et al., 2020) Adequate personal protective equipment (PPE), well-being support, and lower exposure to moral dilemmas have been found to be among the factors that alleviate the psychological effects. (Wanigasooriya et al., 2020).

According to Maslach, burnout syndrome is the totality of symptoms among professionals who are obliged to work face-to-face with other people and are frequently exposed to emotional demands, including fatigue and exhaustion, feelings of hopelessness and despair, and negativity towards work, life, and also other people because of their work. According to Maslach, burnout is composed of three dimensions: emotional exhaustion, depersonalization, and low sense of personal accomplishment (C Maslach, 1982). Environmental factors are as important as personal factors in the development of burnout syndrome. Due to the nature of their occupation, physicians are at particular risk for burnout syndrome. One review conducted in China in 2018 evaluated 9302 physicians and found that $66.5-87.8 \%$ exhibited burnout symptoms (Lo et al., 2018). It may be hypothesized that events that increase the levels of stress in healthcare professionals, such as the pandemic, may exacerbate the incidence of burnout syndrome in physicians (Sasangohar et al., 2020). It was demonstrated that the healthcare personnel working at the COVID units have an increased need for psychological support (Trumello et al., 2020). 
Studies have shown that psychological symptoms which occur during a pandemic may become permanent (Lam et al., 2009). Meeting the emotional needs of healthcare workers is therefore of great importance. This study was intended to investigate levels of depression, anxiety, and burnout in healthcare professionals in Turkey during the pandemic and to identify the factors affecting these variables. Our hypothesis is that the incidence of these mental conditions is elevated among healthcare workers in Turkey. Moreover, these symptoms are thought to be influenced by parameters such as gender, fear of transmitting the disease to loved ones, and inadequate working conditions.

\section{Method}

The population of this descriptive study consisted of physicians working in various health institutions in Turkey. Data were obtained between April 23 and 27, 2020, via online questionnaires sent to participants' smartphones using SurveyMonkey software (SurveyMonkey, San Mateo, CA, USA). Four hundred six physicians were reached this way.

\section{Data Collection Tools}

The questionnaire consisted of 54 items including sociodemographic data and questions pertaining to the Hospital Anxiety and Depression Scale (HADS) and the Maslach Burnout Inventory (MBI).

HADS was developed by Zigmond and Snaith (1983) and is a self-assessment scale used to determine levels of anxiety and depression. The scale consists of 14 items (Zigmond and Snaith, 1983). Each item is scored between 0 and 3. Anxiety and depression are assessed with 7 items each, and both depression and anxiety are scored from 0 to 21 . Increased scores indicate greater severity of depression and anxiety. The validity and reliability of the Turkish-language version was investigated by Aydemir et al. Cut-off scores of 7 for depression and 10 for anxiety were determined for the Turkish population (Aydemir et al., 1997). Here, we note other validity and reliability studies on various ethnicities (Hajian-Tilaki and Hajian-Tilaki, 2020; Risal et al., 2015).

The MBI is a self-assessment scale developed by Maslach and Jackson consisting of 22 items (C. Maslach and Jackson, 1981) and translated into various languages (Wickramasinghe et al., 2018; Yuen et al., 2002). It was adapted into Turkish by Ergin et al. (Ergin, 1996). The scale consists of three subscales: emotional exhaustion which assesses the individual's emotional overextension and exhaustion, depersonalization which assesses unfeeling and impersonal responses towards recipients of care, and personal accomplishment which assesses feelings of competence and successful achievement towards the work undertaken. Emotional exhaustion is assessed with 9 items, depersonalization with 5 items, and personal accomplishment with 8 items. Responses to the items are based on the frequency of the symptom, ranging from never to always. Each item is scored from 0 to 4. Emotional exhaustion and depersonalization scores are directly proportional to the level of burnout, while personal accomplishment scores are inversely proportional. Emotional exhaustion scores range between 0 and 36, depersonalization scores between 0 and 20, and personal accomplishment scores between 0 and 32 .

\section{Statistical Analysis}

Statistical analysis was performed using the SPSS 22.0 package program. For ease of interpretation, results were expressed as mean \pm standard deviation and percentage $(\%)$. The 
Kolmogorov Smirnov test was used to assess the normality of the distribution of quantitative data. Our analysis indicated that the data were suitable for the use of non-parametric tests. Qualitative data were compared using the Chi-square test. The Mann-Whitney $U$ test was used for two-group comparisons, while the Kruskal-Wallis test was used for comparison between multiple groups. Participants were classified as those with anxiety and depression according to HADS cut-off scores, and Binary Logistic Regression Analysis was used to identify factors associated with anxiety and depression. Multiple Linear Regression Analysis was used to determine factors associated with MBI subscales. $p$ values lower than 0.05 were considered statistically significant for all tests. Approval for the study was granted by the Ondokuz Mayis University Clinical Research Ethical Committee (No. 2020/162).

\section{Results}

The mean age of the 406 physicians who participated in the study was $42.9 \pm 10.1$ years, and $53.4 \%$ were men ( $n: 217)$. The mean length of employment was $18.6 \pm 10.1$ years, with $46.8 \%$ $(n: 190)$ of participants working as specialists and $27.8 \%(n: 113)$ as general practitioners. In total, $22.2 \%$ of participants were working in Training-Research Hospitals ( $n: 90)$ and $21.8 \%$ in Family Health Centers (FHCs) ( $n$ : 86). Participants' sociodemographic and occupational characteristics are presented in Table 1.

At least one chronic disease was observed in $27.8 \%$ ( $n$ : 113) of physicians, while $11.1 \%(n$ : $45)$ had a current psychiatric disorder, and $25.4 \%$ ( $n: 103)$ had a history of psychiatric disorder. In addition, $63.3 \%(n: 257)$ were non-smokers. Among the smokers, $65.1 \%(n: 97)$ had cut down on or discontinued smoking during the pandemic, while $27.5 \%(n: 41)$ continued smoking as usual, and $7.4 \%(n$ : 11$)$ were smoking more.

Table 1 Sociodemographic and occupational characteristics of the participants

\begin{tabular}{llr}
\hline Variables & & $n(\%)$ \\
\hline Gender & Male & $217(53.4)$ \\
& Female & $189(46.6)$ \\
Age, years (mean \pm SD) & & $42.9 \pm 10.1$ \\
Marital status & Married & $297(73.2)$ \\
& Single* & $109(26.8)$ \\
Total number of people in the household $(n \pm$ SD) & & $3.1 \pm 1.3$ \\
Working years, years (mean \pm SD) & & $18.6 \pm 10.1$ \\
Title & GP & $113(27.8)$ \\
& RA & $58(14.3)$ \\
& Specialist & $190(46.8)$ \\
Field (for titles other than general practitioner) $(n: 293)$ & Academic staff & $45(11.1)$ \\
& Internal medical sciences & $178(60.7)$ \\
Institution of employment & Surgical medical sciences & $106(36.1)$ \\
& Basic medical sciences & $9(3.2)$ \\
& TRH & $90(22.2)$ \\
& FHC & $86(21.8)$ \\
& Public hospital & $79(19.5)$ \\
& University hospital & $69(17.0)$ \\
\hline
\end{tabular}

$G P$ general practitioner, $R A$ research assistant, $T R H$ training-research hospital, $F H C$ family health center. *Divorced and widowed individuals are grouped together with single subjects due to their very low numbers 
While $66.7 \%$ (n:271) of the physicians reported reduced working hours, $21.9 \%$ (n:89) had the same working hours, and $11.3 \%$ (n:46) reported increased working hours. In addition, $46.3 \%$ (n:188) were working in COVID-19 units, $45.3 \%$ (n:184) had received training related to COVID-19. and 50.2\% (n:204) had experienced difficulty in obtaining PPE. In total, $81.5 \%$ $(n: 331)$ of the physicians feared spreading the virus to their families.

Comparisons between the subgroups revealed that depression scores were higher among female physicians $(p<0.001)$, general practitioners $(p 0.017)$, physicians working in surgical branches $(p$ 0.018), among those who experienced difficulty in obtaining PPE $(p<0.001)$, those fear of infecting relatives ( $p$ 0.018), and those with an current $(p<0.001)$ or previous $(p$ $0.002)$ psychiatric disorder. Anxiety scores were significantly higher among female physicians $(p<0.001)$, general practitioners $(p 0.001)$, those working in FHCs $(p 0.002)$, those who experienced difficulty in obtaining PPE $(p<0.001)$, those fear of infecting relatives $(p 0.012)$, and those with a current $(p<0.001)$ or previous $(p<0.001)$ psychiatric disorder. Mean HADS scores and statistical analyses of subgroups are presented in Table 2.

MBI emotional exhaustion subscale scores were significantly high in female ( $p$ 0.001 ), single individuals ( $\mathrm{p}$ 0.004), general practitioners and research assistants $(p<$ $0.001)$, physicians working in FHCs $(p<0.001)$, those with increased working hours $(p$ 0.027), without COVID-19 training ( $p$ 0.002), who experienced difficulty in obtaining $\operatorname{PPE}(p<0.001)$, and with current $(p<0.001)$ or previous $(p<0.001)$ psychiatric disorders. MBI depersonalization subscales scores were significantly high among general practitioners and research assistants $(p<0.001)$, participants without COVID-19 training ( $p$ 0.038), who experienced difficulty in obtaining PPE $(p<0.001)$, and with previous psychiatric disorders $(p$ 0.005). Physicians working in COVID units had high depersonalization scores approaching a level of statistical significance $(p=0.051)$. Personal accomplishment subscale scores were low among research assistants $(p<0.001)$, and in participants working in university and research and training hospitals $(p 0.007)$, who experienced difficulty in obtaining PPE $(p<0.001)$, and those who had a psychiatric disorder in the past ( $p$ 0.035). Physicians without COVID-19 training had low personal accomplishment scores approaching statistical significance $(p=0.051)$. Comparisons of MBI subscale scores between subgroups are presented in Table 3.

In terms of HADS scores, 171 (42.1\%) participants had depression scores above the cut-off point, and $174(42.9 \%)$ had anxiety scores above the cut-off. Multiple binary logistic regression analysis evaluating the risk factors for depression and anxiety identified working in surgical branches ( $p$ 0.034), working in FHCs ( $p$ 0.044), experiencing difficulty in obtaining PPE $(p<0.001)$, and fear of infecting relatives $(p 0.032)$ as risk factors for depression, and female gender ( $p$ 0.001), working in FHCs $(p<0.001)$, difficulty in obtaining PPE $(p<0.001)$, fear of infecting relatives $(p 0.027)$ and current psychiatric illness $(p 0.018)$ as risk factors for anxiety (Table 4).

Multiple linear regression analysis of MBI subscales identified working as a general practitioner ( $p$ 0.033), lack of COVID training ( $p$ 0.0.004), difficulty in obtaining PPE $(p<0.001)$, working in COVID units $(p$ 0.005), and current psychiatric illness $(p 0.011)$ as predictors of emotional exhaustion. Female gender $(p 0.043)$, working as a general practitioner (0.036), lack of COVID training ( $p$ 0.003), difficulty in obtaining PPE $(\mathrm{p}<0.001)$, working in COVID units ( $p$ 0.004), and previously having a psychiatric disorder were identified as predictors of depersonalization, while lack of COVID training ( $p 0.001)$, difficulty in obtaining PPE ( $p$ 0.022), and working in COVID units ( $p$ 0.011) were identified as predictors of loss of personal accomplishment (Table 5). 


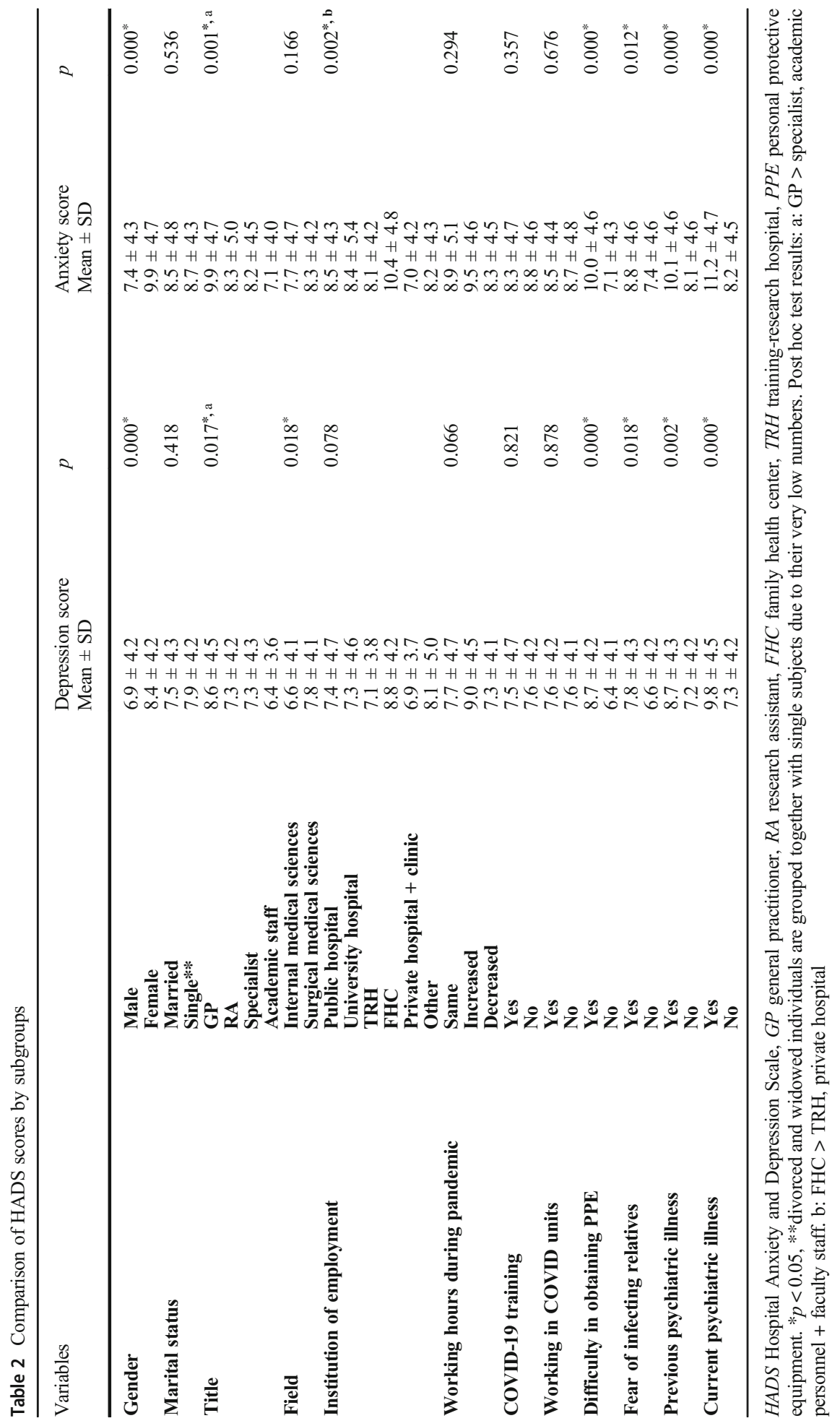




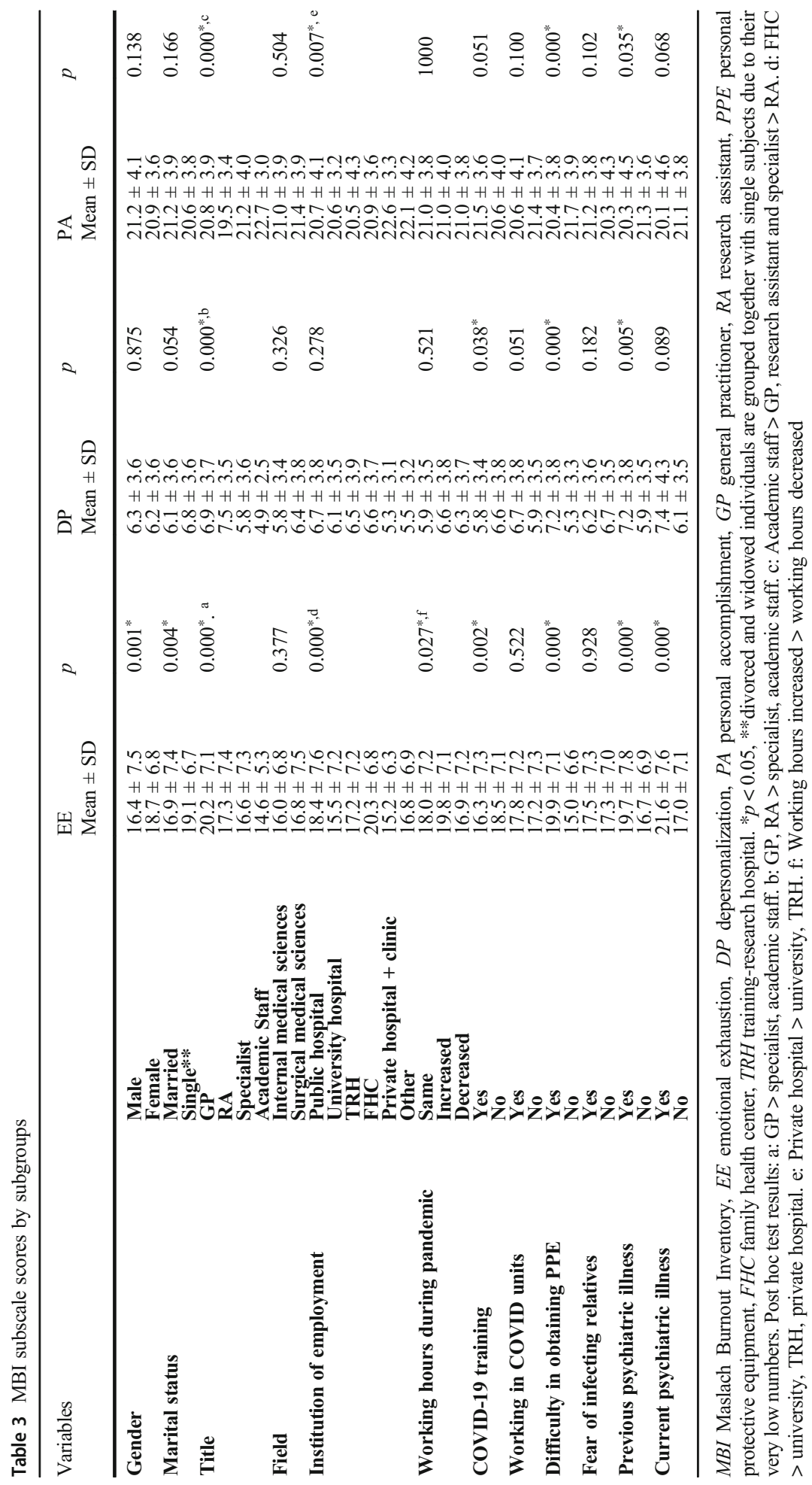


Table 4 Results of binary logistic regression analysis for factors significantly associated with depression and anxiety

\begin{tabular}{|c|c|c|c|c|}
\hline & \multicolumn{2}{|c|}{$\begin{array}{l}\text { Depression ( } n: 171) \text { vs no } \\
\text { depression }(n: 235)\end{array}$} & \multicolumn{2}{|l|}{$\begin{array}{l}\text { Anxiety ( } n: 174) \text { vs } \\
\text { no anxiety }(n: 232)\end{array}$} \\
\hline & AOR $(95 \% \mathrm{CI})$ & $p$ & AOR $(95 \% \mathrm{CI})$ & $p$ \\
\hline Gender (female vs male) & $1.501(0.964 ; 2.340)$ & 0.073 & $1.452(1.288 ; 1.709)$ & $0.001^{*}$ \\
\hline Age & $1.000(0.976 ; 1.024)$ & 0.980 & $0.999(0.975 ; 1.024)$ & 0.948 \\
\hline Working hours (increased vs others) & $0.503(0.236 ; 1.070)$ & 0.075 & $1.114(0.542 ; 2.290)$ & 0.769 \\
\hline Title (GP vs others) & $1.112(0.660 ; 1.871)$ & 0.690 & $0.646(0.385 ; 1.083)$ & 0.098 \\
\hline Branch (surgical vs internal medicine) & $1.590(1.362 ; 1.962)$ & $0.034^{*}$ & $1.342(0.817 ; 2.206)$ & 0.246 \\
\hline Institution of employment (FHC vs others) & $1.598(1.362 ; 1.987)$ & $0.044^{*}$ & $2.641(1.618 ; 4.311)$ & $<0.001^{*}$ \\
\hline Working in COVID units (yes vs no) & $0.872(0.545 ; 1.395)$ & 0.568 & $1.104(0.676 ; 1.800)$ & 0.693 \\
\hline COVID training (no vs yes) & $1.111(0.714 ; 1.728)$ & 0.641 & $0.976(0.620 ; 1.536)$ & 0.915 \\
\hline Difficulty in obtaining PPE (yes vs no) & $1.389(1.251 ; 1.605)$ & $<0.001^{*}$ & $2.720(1.734 ; 4.265)$ & $<0.001^{*}$ \\
\hline Fear of infecting relatives (yes vs no) & $1.548(1.316 ; 1.950)$ & $0.032^{*}$ & $1.999(1.084 ; 3.687)$ & $0.027^{*}$ \\
\hline Current chronic disease (yes vs no) & $0.753(0.439 ; 1.292)$ & 0.303 & $0.985(0.574 ; 1.690)$ & 0.957 \\
\hline Current psychiatric illness (yes vs no) & $0.612(0.258 ; 1.454)$ & 0.266 & $2.732(1.185 ; 6.297)$ & $0.018^{*}$ \\
\hline Previous psychiatric illness (yes vs no) & $0.721(0.397 ; 1.308)$ & 0.282 & $1.232(0.686 ; 2.213)$ & 0.485 \\
\hline
\end{tabular}

HADS Hospital Anxiety and Depression Scale, AOR adjusted odds ratio, $C I$ confidence interval, GP general practitioner, $F H C$ family health center, $P P E$ personal protective equipment. * $p<0.05$

\section{Discussion}

The mean age of the 406 physicians who participated in the study was $42.9 \pm 10.1$ years and $53.4 \%$ were men. The mean length of employment was $18,6 \pm 10.1$ years, $46.8 \%$ of participants were specialists and $27.8 \%$ (n:113) were general practitioners. During the pandemic, $66.7 \%$ of participants reported decreased working hours, $46.3 \%$ of physicians were working in COVID-19 units, and $45.3 \%$ had received COVID-19 training.

A recent study on healthcare professionals in China during the COVID-19 pandemic reported that $70 \%$ had various psychiatric disturbances, particularly depression and anxiety (J. Lai et al., 2020). In a study conducted during the SARS outbreak, 89\% of healthcare workers were found to have exhibited negative psychological responses (Chua et al., 2004). Healthcare professionals display a range of psychological responses towards the outbreaks. These may be due to feelings of vulnerability and, feelings of loss of control, fear of infecting family members and colleagues with the virus, work-related changes, and concerns about isolation from the community (Wong et al., 2005). Evaluation of the subgroups of our study revealed that depression and anxiety scores were higher among female physicians, general practitioners, individuals who experienced difficulty in obtaining PPE, who feared infecting their families, and those with current or previous psychiatric illness. Physicians working in surgical branches had higher depression scores, while those working in FHCs had significantly higher anxiety scores. Studies from China suggest an association between the severity of the psychological response and female gender, as well as a more junior professional title (J. Lai et al., 2020). It has been shown that women feel more fear than men during the COVID-19 pandemic (Broche-Pérez et al., 2020). In addition, the high interpersonal contagiousness and morbidity of COVID-19 may intensify the perception of threat among individuals. Problems in the provision of PPE may also increase employee difficulty and concerns. Another cause of high scores among general practitioners may be insecurity due to unconfirmed diagnoses in their patients. At the same time, the fact that many hospitals have been converted into 


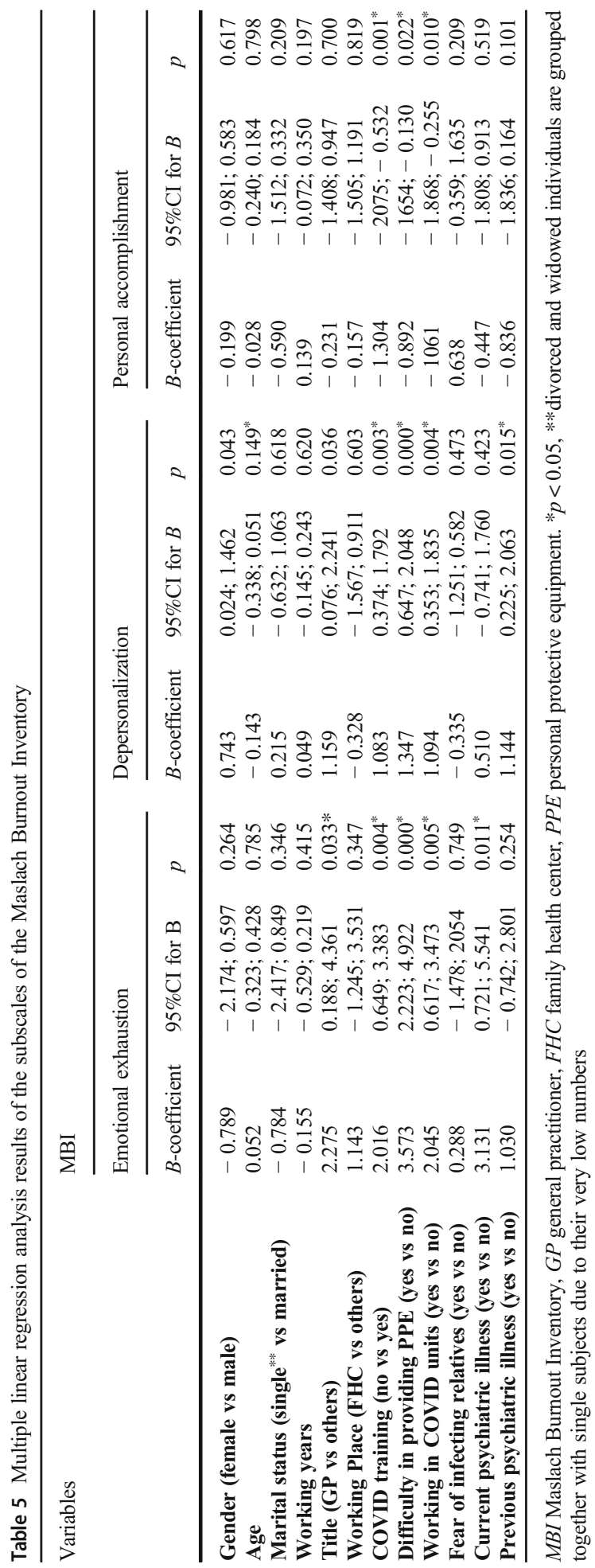


pandemic hospitals increases the FHCs' burden, further exacerbating the severity of psychological responses among general practitioners. For this reason, increased levels of anxiety and depression among the physicians found in our study is consistent with earlier reports.

In Turkey, it is general practitioners who first encounter patients in emergency departments, and these constitute one of the highest risk groups due to close and frequent contact. At the same time, each examination may pose a potential risk of infection as this is when patients are first encountered in emergency departments. Consequently, the general practitioners are more likely to experience the psychological effects of the pandemic. Studies from Hubei and Wuhan have observed higher anxiety and depression levels among general practitioners and emergency department workers (J. Lai et al., 2020). It has been shown that the fear of coronavirus reduces resilience against depression and anxiety (Yıldırım et al., 2020). The mental wellbeing and psychiatric assessment of general practitioners who work in the front line against COVID are therefore of the utmost importance.

The findings of studies investigating the relationship between the unit of employment or working in a COVID unit and mental health are inconsistent. In the present study, variables associated with mental health among workers in COVID units were similar to those of individuals not working in such units. However, there are also studies showing no increase in psychological problems among individuals working in COVID units (Liang et al., 2020; Spoorthy et al., 2020). In fact, one study observed that healthcare professionals working in direct contact with infected patients were less anxious about becoming infected (Wu et al., 2020). Working in the front line may actually be a protective factor in terms of mental health because such individuals tend to be closer to disease-related decision-makers and have access to current and more accurate information related to the disease and modes of protection against it (Reddy et al., 2020). Other studies have found that physicians working in emergency departments, intensive care units, and COVID-19 units were at greater risk of developing psychiatric symptoms (Naushad et al., 2019). In a study from China which compared geographical regions and mental health outcomes, 1257 participants were grouped as those working in Wuhan, in other regions in Hubei, and in regions outside Hubei. The results of the study showed that healthcare workers in Wuhan, the origin and center of the pandemic, had more severe symptoms of depression and anxiety, while those working outside Hubei experienced less distress (J. Lai et al., 2020). Due to the manner of infection and its rapid spread, individuals living in regions with a risk of infection may be at a greater risk of developing depression and anxiety because of fear of spreading the virus to their families (Ho et al., 2020). Our results identified fear of spreading the virus as a predictor of depression and anxiety.

An increase in the number of suspected infected patients admitted to hospital due to the growth in the daily number of confirmed cases may lead to burnout and physical and mental fatigue among healthcare personnel. In addition, intense feelings of despair, hopelessness, and isolation in some healthcare workers infected with COVID-19 also leads to burnout (Xiang et al., 2020). Previous studies have shown that low working experience, increased weekly working hours, working on weekends, and low numbers of personnel in the work team are also related to burnout (Kamal et al., 2019). Although participants working in COVID units in our study were found to have high burnout scores, one study from China observed that healthcare workers on the front line had experienced less burnout in the previous 2 months. Although the COVID-19 pandemic falls within the primary sphere of interest of the Chest Diseases and Infectious Diseases departments, many physicians from different branches have been assigned to COVID units and perform examinations on COVID patients since the start of the pandemic. Accordingly, working environments 
and working hours, and roles in the working environment have changed. Workers who have not received COVID training and those who have difficulty in obtaining PPE may experience more burnout because they lack sufficient information about the new protocols and procedures which have been implemented to keep personnel and patients safe (Reddy et al., 2020). General surgery residents, who work on the front line against COVID, have requested provision of PPE and organized working hours before working in COVID units (He et al., 2020). The fact that difficulty in obtaining PPE may increase levels of burnout in physicians actively working with COVID is therefore an expected outcome.

Studies evaluating levels of depersonalization have reported intense working hours, sleep disorders, and mental well-being as associated factors. Depersonalization was especially high among physicians and may be due to a gradual decrease in physicians' ability to invest emotionally in their work. Individuals working in COVID units need to respond to patients more quickly and effectively, and doctors have to set their feelings aside during these interventions. In addition, lack of COVID training and experiencing difficulty in obtaining PPE may result in negative perceptions of their work and capabilities among physicians, and in decreased self-esteem and feelings of self-sufficiency. This may cause them to distance themselves from patients and become desensitized (Moukarzel et al., 2019).

Studies have indicated that, although healthcare professionals face many physical and psychological challenges, they are also confident of overcoming the pandemic. Factors associated with feelings of personal accomplishment include access to sufficient protective equipment, regular working hours, high work experience, effective communication environment, and infection control being monitored and inspected (Xiong and Peng, 2020). Some studies from Wuhan have reported that individuals closely involved with patients infected with COVID-19 felt a deeper sense of accomplishment. This may be due to their directly observing the results and, as a result, contributing to reducing the outbreak (Reddy et al., 2020). Providing healthcare personnel with training and medical support has been shown to reduce levels of anxiety and stress, and the individual's selfsufficiency thus increases (Xiao et al., 2020).

Increased workload has been shown to be the most important cause of burnout in healthcare workers. Moreover, it is known that procedural justice and professional identification are effective in preventing burnout (Correia and Almeida, 2020). Based on the literature referred to above, the findings that could be predictive of all three components of burnout are: not having received COVID training, having difficulties in obtaining PPE, and working in COVID units.

According to the results of the present study and the literature in general, factors associated with mental health related to COVID-19 include family safety, adequacy of precautions taken against infection, and training (Cai et al., 2020). In addition, health workers' needs and challenges vary during the course of an outbreak. Studies of the SARS outbreak have shown that $18-57 \%$ of healthcare professionals experienced emotional distress at the beginning, during, and after the outbreak (Phua et al., 2005). It must not be forgotten that physicians face post-traumatic stress disorder, depression, anxiety, and burnout, even after the pandemic has ended (Lee et al., 2018). However, despite all these mental challenges, healthcare workers were observed to be highly resilient and to exhibit a strong spirit of teamwork throughout the outbreak (Duan and Zhu, 2020). Nevertheless, in order to minimize the risk of psychiatric illnesses in healthcare professionals, screening should be carried out to identify early symptoms of burnout, anxiety, and depression, and professional counseling should be provided in case of these symptoms (Xiang et al., 2020). 
One limitation of this study was that psychological assessment was based solely on selfassessment scales, without interviews by specialists. Therefore, the outcome of the study may have been influenced by the subjectivity of the obtained data. In addition, the participants who did not use a smartphone could not be included in the study. For this reason, a selection bias may have occurred. Because of the nature of the cross-sectional data, it is difficult to make causal interferences.

\section{Conclusion}

This study examined the mental health as well as the factors affecting the mental health of the physicians during the COVID-19 pandemic. Physicians face various difficulties during outbreaks, such as the risk of infection, inadequate personal protective equipment, burnout, and the fear of infecting their families. These may lead to mental conditions such as anxiety, depression, and burnout. Providing continuous and comprehensive support mechanisms for physicians in order to protect their mental health during an outbreak is of great importance.

\section{Declarations}

Ethics Approval and Consent to Participate All procedures followed were in accordance with the ethical standards of the responsible committee on human experimentation (institutional and national) and with the Helsinki declaration of 1975, as revised in 2000. Informed consent was obtained from all patients for being included in the study.

Conflict of Interest The authors declare no competing interests.

\section{References}

Aydemir, O., Güvenir, T., Küey, L., \& Kültür, S. (1997). Hastane Anksiyete ve Depresyon Ölçeği Türkçe Formunun Geçerlilik ve Güvenilirlik Çalıșması. Reliability and Validity of the Turkish version of Hospital Anxiety and Depression Scale. Türk Psikiyatri Dergisi, 8, 280-287.

Bai, Y., Lin, C. C., Lin, C. Y., Chen, J. Y., Chue, C. M., \& Chou, P. (2004). Survey of stress reactions among health care workers involved with the SARS outbreak. Psychiatric Services, 55(9), 1055-1057. https://doi. org/10.1176/appi.ps.55.9.1055.

Brahmi, N., Singh, P., Sohal, M., \& Sawhney, R. S. (2020). Psychological trauma among the healthcare professionals dealing with COVID-19. Asian Journal of Psychiatry, 54, 102241-102241. https://doi.org/ 10.1016/j.ajp.2020.102241.

Broche-Pérez, Y., Fernández-Fleites, Z., Jiménez-Puig, E., Fernández-Castillo, E., \& Rodríguez-Martin, B. C. (2020). Gender and fear of COVID-19 in a Cuban population sample. International Journal of Mental Health and Addiction. https://doi.org/10.1007/s11469-020-00343-8.

Cai, H. Z., Tu, B. R., Ma, J., Chen, L. M., Fu, L., Jiang, Y. F., \& Zhuang, Q. (2020). Psychological impact and coping strategies of frontline medical staff in Hunan between January and march 2020 during the outbreak of coronavirus disease 2019 (COVID-19) in Hubei, China. Medical Science Monitor, 26, 924171. doi:ARTN e924171. https://doi.org/10.12659/MSM.924171.

Chua, S. E., Cheung, V., Cheung, C., McAlonan, G. M., Wong, J. W., Cheung, E. P., Chan, M. T. Y., Wong, M. M. C., Tang, S. W., Choy, K. M., Wong, M. K., Chu, C. M., \& Tsang, K. W. (2004). Psychological effects of the SARS outbreak in Hong Kong on high-risk health care workers. Canadian Journal of Psychiatry, 49(6), 391-393. https://doi.org/10.1177/070674370404900609.

Correia, I., \& Almeida, A. E. (2020). Organizational justice, professional identification, empathy, and meaningful work during COVID-19 pandemic: Are they burnout protectors in physicians and nurses? Frontiers in Psychology, 11, 566139. https://doi.org/10.3389/fpsyg.2020.566139. 
da Silva, F. C. T., \& Neto, M. L. R. (2021). Psychiatric symptomatology associated with depression, anxiety, distress, and insomnia in health professionals working in patients affected by COVID-19: A systematic review with meta-analysis. Progress in Neuro-Psychopharmacology \& Biological Psychiatry, 104, 110057110057. https://doi.org/10.1016/j.pnpbp.2020.110057.

Duan, L., \& Zhu, G. (2020). Psychological interventions for people affected by the COVID-19 epidemic. The Lancet Psychiatry, 7(4), 300-302.

Ergin, C. (1996). Maslach tükenmișlik ölçeğinin Türkiye sağlık personeli normları. Psikiyatri Psikoloji Psikofarmakoloji (3P) Dergisi, 4(1), 28-33.

Hajian-Tilaki, K., \& Hajian-Tilaki, E. (2020). Factor structure and reliability of Persian version of hospital anxiety and depression scale in patients with breast cancer survivors. Health and Quality of Life Outcomes, 18(1), 176. https://doi.org/10.1186/s12955-020-01429-6.

HASUDER. (2020). Retrieved from https://korona.hasuder.org.tr/. Accessed 01/06/2020.

He, K., Stolarski, A., Whang, E., \& Kristo, G. (2020). Addressing general surgery residents' concerns in the early phase of the COVID-19 pandemic. Journal of Surgical Education, 77, 735-738. https://doi.org/10.1016/j. jsurg.2020.04.003.

Ho, C. S., Chee, C. Y., \& Ho, R. C. (2020). Mental health strategies to combat the psychological impact of COVID-19 beyond paranoia and panic. Annals of the Academy of Medicine, Singapore, 49(3), 155-160.

İstanbul Medical Association. (2020). Retrieved from https://www.istabip.org.tr/koronavirus/. Accessed 01/06/ 2020

Kamal, A. H., Bull, J. H., Wolf, S. P., Swetz, K. M., Shanafelt, T. D., Ast, K., et al. (2019). Prevalence and predictors of burnout among hospice and palliative care clinicians in the US. Journal of Pain and Symptom Management.

Lai, J., Ma, S., Wang, Y., Cai, Z., Hu, J., Wei, N., Wu, J., du, H., Chen, T., Li, R., Tan, H., Kang, L., Yao, L., Huang, M., Wang, H., Wang, G., Liu, Z., \& Hu, S. (2020). Factors associated with mental health outcomes among health care workers exposed to coronavirus disease 2019. JAMA Network Open, 3(3), e203976. https://doi.org/10.1001/jamanetworkopen.2020.3976.

Lam, M. H., Wing, Y. K., Yu, M. W., Leung, C. M., Ma, R. C., Kong, A. P., So, W. Y., Fong, S. Y., \& Lam, S. P. (2009). Mental morbidities and chronic fatigue in severe acute respiratory syndrome survivors: Long-term follow-up. Archives of Internal Medicine, 169(22), 2142-2147. https://doi.org/10.1001/archinternmed.2009. 384.

Lee, S. M., Kang, W. S., Cho, A. R., Kim, T., \& Park, J. K. (2018). Psychological impact of the 2015 MERS outbreak on hospital workers and quarantined hemodialysis patients. Comprehensive Psychiatry, 87, 123127. https://doi.org/10.1016/j.comppsych.2018.10.003.

Liang, Y., Chen, M., Zheng, X., \& Liu, J. (2020). Screening for Chinese medical staff mental health by SDS and SAS during the outbreak of COVID-19. Journal of Psychosomatic Research, 133, 110102. https://doi.org/ 10.1016/j.jpsychores.2020.110102.

Lo, D., Wu, F., Chan, M., Chu, R., \& Li, D. (2018). A systematic review of burnout among doctors in China: A cultural perspective. Asia Pacific Family Medicine, 17, 3. https://doi.org/10.1186/s12930-018-0040-3.

Lung, F. W., Lu, Y. C., Chang, Y. Y., \& Shu, B. C. (2009). Mental symptoms in different health professionals during the SARS attack: A follow-up study. The Psychiatric Quarterly, 80(2), 107-116. https://doi.org/10. 1007/s11126-009-9095-5.

Maslach, C. (1982). The cost of caring. Practice Hall Inc.

Maslach, C., \& Jackson, S. E. (1981). The measurement of experienced burnout. Journal of Occupational Behaviour, 2(2), 99-113. https://doi.org/10.1002/job.4030020205.

Morgantini, L. A., Naha, U., Wang, H., Francavilla, S., Acar, Ö., Flores, J. M., Crivellaro, S., Moreira, D., Abern, M., Eklund, M., Vigneswaran, H. T., \& Weine, S. M. (2020). Factors contributing to healthcare professional burnout during the COVID-19 pandemic: A rapid turnaround global survey. PLoS One, 15(9), e0238217. https://doi.org/10.1371/journal.pone.0238217.

Moukarzel, A., Michelet, P., Durand, A. C., Sebbane, M., Bourgeois, S., Markarian, T., Bompard, C., \& Gentile, S. (2019). Burnout syndrome among emergency department staff: Prevalence and associated factors. BioMed Research International, 2019, 6462472-6462410. https://doi.org/10.1155/2019/6462472.

Naushad, V. A., Bierens, J. J., Nishan, K. P., Firjeeth, C. P., Mohammad, O. H., Maliyakkal, A. M., ChaliHadan, S., \& Schreiber, M. D. (2019). A systematic review of the impact of disaster on the mental health of medical responders. Prehospital and Disaster Medicine, 34(6), 632-643. https://doi.org/10.1017/ S1049023X19004874.

Phua, D. H., Tang, H. K., \& Tham, K. Y. (2005). Coping responses of emergency physicians and nurses to the 2003 severe acute respiratory syndrome outbreak. Academic Emergency Medicine, 12(4), 322-328. https:// doi.org/10.1197/j.aem.2004.11.015. 
Reddy, S. K., Yennu, S., Tanco, K., Anderson, A., Guzman, D., Naqvi, S. M. A., et al. (2020). Frequency of burn-out among palliative care physicians participating in a continuing medical education course. Journal of Pain and Symptom Management, 60, 80-86.e2.

Risal, A., Manandhar, K., Linde, M., Koju, R., Steiner, T. J., \& Holen, A. (2015). Reliability and validity of a Nepali-language version of the hospital anxiety and depression scale (HADS). Kathmandu University of Medical Journal (KUMJ), 13(50), 115-124. https://doi.org/10.3126/kumj.v13i2.16783.

Sasangohar, F., Jones, S. L., Masud, F. N., Vahidy, F. S., \& Kash, B. A. (2020). Provider burnout and fatigue during the COVID-19 pandemic: Lessons learned from a high-volume intensive care unit. Anesthesia and Analgesia, 131(1), 106-111. https://doi.org/10.1213/ANE.0000000000004866.

Spoorthy, M. S., Pratapa, S. K., \& Mahant, S. (2020). Mental health problems faced by healthcare workers due to the COVID-19 pandemic-a review. Asian Journal of Psychiatry, 51, 102119. https://doi.org/10.1016/j.ajp. 2020.102119.

Şahin, B., Hoșoğlu, E., \& Önal, B. (2020). Anxiety symptoms in healthcare workers and their children during the covid-19 pandemic in Turkey. Namık Kemal Tip Dergisi, 8(3), 321-330.

Trumello, C., Bramanti, S. M., Ballarotto, G., Candelori, C., Cerniglia, L., Cimino, S., Crudele, M., Lombardi, L., Pignataro, S., Viceconti, M. L., \& Babore, A. (2020). Psychological adjustment of healthcare Workers in Italy during the COVID-19 pandemic: Differences in stress, anxiety, depression, burnout, secondary trauma, and compassion satisfaction between frontline and non-frontline professionals. International Journal of Environmental Research and Public Health, 17(22). https://doi.org/10.3390/ijerph17228358.

Wanigasooriya, K., Palimar, P., Naumann, D. N., Ismail, K., Fellows, J. L., Logan, P., Thompson, C. V., Bermingham, H., Beggs, A. D., \& Ismail, T. (2020). Mental health symptoms in a cohort of hospital healthcare workers following the first peak of the COVID-19 pandemic in the UK. BJPsych Open, 7(1), e24. https://doi.org/10.1192/bjo.2020.150.

Wickramasinghe, N. D., Dissanayake, D. S., \& Abeywardena, G. S. (2018). Validity and reliability of the Maslach burnout inventory-student survey in Sri Lanka. BMC Psychology, 6(1), 52. https://doi.org/10.1186/ s40359-018-0267-7.

Wong, T. W., Yau, J. K. Y., Chan, C. L. W., Kwong, R. S. Y., Ho, S. M. Y., Lau, C. C., et al. (2005). The psychological impact of severe acute respiratory syndrome outbreak on healthcare workers in emergency departments and how they cope. European Journal of Emergency Medicine, 12(1), 13-18. https://doi.org/10. 1097/00063110-200502000-00005.

Wu, Y., Wang, J., Luo, C., Hu, S., Lin, X., Anderson, A. E., Bruera, E., Yang, X., Wei, S., \& Qian, Y. (2020). A comparison of burnout frequency among oncology physicians and nurses working on the frontline and usual wards during the COVID-19 epidemic in Wuhan, China. Journal of Pain and Symptom Management, 60, e60-e65. https://doi.org/10.1016/j.jpainsymman.2020.04.008.

Xiang, Y. T., Jin, Y., Wang, Y., Zhang, Q., Zhang, L., \& Cheung, T. (2020). Tribute to health workers in China: A group of respectable population during the outbreak of the COVID-19. International Journal of Biological Sciences, 16(10), 1739-1740. https://doi.org/10.7150/ijbs.45135.

Xiao, H., Zhang, Y., Kong, D., Li, S., \& Yang, N. (2020). The effects of social support on sleep quality of medical staff treating patients with coronavirus disease 2019 (COVID-19) in January and February 2020 in China. Medical Science Monitor, 26, e923549. https://doi.org/10.12659/MSM.923549.

Xiong, Y., \& Peng, L. (2020). Focusing on health-care providers' experiences in the COVID-19 crisis. The Lancet Global Health, 8(6), e740-e741. https://doi.org/10.1016/s2214-109x(20)30214-x.

Yıldırım, M., Arslan, G., \& Özaslan, A. (2020). Perceived risk and mental health problems among healthcare professionals during COVID-19 pandemic: Exploring the mediating effects of resilience and coronavirus fear. International Journal of Mental Health and Addiction. https://doi.org/10.1007/s11469-020-00424-8.

Yuen, M., Lau, P. S., Shek, D. T., \& Lam, M. P. (2002). Confirmatory factor analysis and reliability of the Chinese version of the Maslach Burnout Inventory among guidance teachers in Hong Kong. Psychological Reports, 91(3 Pt 2), 1081-1086. https://doi.org/10.2466/pr0.2002.91.3f.1081.

Zigmond, A. S., \& Snaith, R. P. (1983). The hospital anxiety and depression scale. Acta Psychiatrica Scandinavica, 67(6), 361-370. https://doi.org/10.1111/j.1600-0447.1983.tb09716.x.

Publisher's Note Springer Nature remains neutral with regard to jurisdictional claims in published maps and institutional affiliations. 